GLOBAL WATER PATHOGEN PROJECT

PART THREE. SPECIFIC EXCRETED PATHOGENS: ENVIRONMENTAL AND EPIDEMIOLOGY ASPECTS

\title{
HEPATITIS E
}

\section{Wim van der Poel}

Central Veterinary Institute - Wageningen UR

Wageningen, Netherlands

\section{Autur Rzezutka}

National Veterinary Research Institute, Pulawy

Puławy, Poland 


\section{Copyright:}

\section{cc) (1) (2) \\ BY SA}

This publication is available in Open Access under the Attribution-ShareAlike 3.0 IGO (CC-BY-SA 3.0 IGO) license (http://creativecommons.org/licenses/by-sa/3.0/igo). By using the content of this publication, the users accept to be bound by the terms of use of the UNESCO Open Access Repository (http://www.unesco.org/openaccess/terms-use-ccbysa-en).

\section{Disclaimer:}

The designations employed and the presentation of material throughout this publication do not imply the expression of any opinion whatsoever on the part of UNESCO concerning the legal status of any country, territory, city or area or of its authorities, or concerning the delimitation of its frontiers or boundaries. The ideas and opinions expressed in this publication are those of the authors; they are not necessarily those of UNESCO and do not commit the Organization.

\section{Citation:}

van der Poel, W. and Rzezutka, A. (2017). Hepatitis E. In: J.B. Rose and B. Jiménez-Cisneros, (eds) Water and Sanitation for the 21st Century: Health and Microbiological Aspects of Excreta and Wastewater Management (Global Water Pathogen Project). (J.S Meschke, and R. Girones (eds), Part 3: Specific Excreted Pathogens: Environmental and Epidemiology Aspects - Section 1: Viruses),

Michigan State University, E. Lansing, MI, UNESCO. https://doi.org/10.14321/waterpathogens.13

Acknowledgements: K.R.L. Young, Project Design editor; Website Design: Agroknow (http://www.agroknow.com)

Last published: August 11, 2017 


\section{Summary}

Hepatitis E virus (HEV) is a small, non-enveloped, single-stranded, positive-sense RNA virus. The genome size is approximately $7.2 \mathrm{~Kb}$. In 2004, Hepatitis E virus (HEV) was designated as the sole member of the genus Hepevirus in the family hepeviridae. Recently, consensus proposals were made to divide the family of Hepeviridae into the genera, Orthohepevirus and Piscihepevirus, of which the genus Orthohepevirus contains all mammalian and avian HEVs. The HEV genome has three open reading frames (ORFs): ORF1 encoding the non-structural polyprotein (nsp), ORF2 encoding the viral capsid protein and ORF3 encoding a small regulatory phosphoprotein. Hepatocytes are assumed to be the primary target cells in which the virus replicates in the cytoplasm. Due to the lack of an efficient cell culture system, the mechanism by which HEV enters the cells and how the virions are released from the cells is not fully understood yet. In humans HEV infections often run an asymptomatic course but after an incubation period of 4 to 5 weeks HEV disease can present like an acute icteric viral hepatitis. Frequently observed symptoms include anorexia, nausea, jaundice, fever and abdominal pain. Mortality rates are generally under $0.5 \%$ but may reach up to $25 \%$ in pregnant women for at least genotype 1 . $\mathrm{HEV}$ is a main cause of epidemic hepatitis in developing countries and single cases of hepatitis in higher income countries. According to the World Health Organisation http://www.who.int/mediacentre/factsheets/fs280/en/) worldwide there are 20 million hepatitis $\mathrm{E}$ infections, over three million acute cases of hepatitis $E$ and 57,000 hepatitis E-related deaths every year.

Orthohepevirus variants most closely related to those infecting humans can be divided into at least four genotypes. Within genotypes 1 to 4 subdivisions into subtypes have been suggested by different authors, based on whole genome sequences or (partial) sequences derived from different open reading frames of the virus genome. An increasing number of HEV sequences are reported and based on findings of divergent lineages in an increasing number of animal species deeper taxonomic groupings and genera have been proposed. Reported lineages of HEV strains within genotypes 1 and 2 are less divergent and seem to be more conserved compared to HEV strains from genotype 3 and 4 . Genotypes 1 and 2 only seem to affect humans. Genotype 1 viruses are predominantly isolated from outbreaks and sporadic cases in Asia and Africa, whereas genotype 2 strains mainly have been observed in outbreaks in Mexico and Africa. Genotypes 3 and 4 are zoonotic and are observed in different animal species and sporadic human cases, worldwide for HEV genotype 3 and mainly in Asia for HEV genotype 4.

HEV in infected individuals is shed enterically and ingestion of HEV particles is assumed to be the most important infection route. The virus may replicate in the intestinal tract but this has not been demonstrated to date. Via the portal vein, HEV can reach the liver, which is believed to be the main HEV target organ. Hepatocytes most likely are the main replication cell type. HEV attaches to host cells via specific high affinity receptors and enters the cytoplasm by clathrin-mediated endocytosis. Virtually nothing is known about the process by which HEV RNA enters target cells. It has been estimated that the infectivity titre of HEV for macaques is 1000 -fold higher when inoculated intravenously compared to when it is ingested; however there is no information on the infectious dose for humans. Before the onset of disease symptoms up to $10^{8} 8$ HEV genome copies per milligram faeces can be excreted for several days. In swine HEV RNA has also been detected in urine and it has been suggested that this may play a role in HEV transmission within this animal reservoir. Aerosol transmission of hepatitis E virus has not been reported. However if infectious HEV is excreted via urine, this route of transmission might be possible too. The concentration of viable virus in an environmental or food matter inoculum may be an important factor in the outcome of clinical hepatitis E infection.

In developing countries HEV outbreaks of mainly genotypes 1 or 2 are generally associated with unhygienic drinking water conditions. In tropical countries HEV epidemics from contaminated drinking water sources are common and affect mainly older children and young adults. Besides the direct infection from a water source horizontal transmission and vertical HEV transmission may play role in outbreaks. Large waterborne HEV outbreaks have recently been reported from Sudan, Chad, India and Pakistan. Improvement of hygienic conditions and decontamination of drinking water will be the most important preventive measurements in these regions.

Foodborne transmission of HEV was first demonstrated in clusters of Japanese patients after eating raw or undercooked meat from swine, wild boar or Sika deer. The genomic sequences of HEVs identified from the infected patients were identical to those recovered from the frozen leftover meat. Through either detection of HEV sequences and/or epidemiological study, more hepatitis E cases have been linked to the consumption of food products contaminated with the virus. This includes infection via locally produced meat products but also from game meat, processed pork, mussels, shellfish and other bivalves. Eating raw or undercooked meat products has been identified as a higher risk factor. Bivalves are known transmitters of enteric viruses and especially oysters are eaten worldwide as raw seafood. More recently HEV sequences have been detected on soft fruits and vegetables, with irrigation water as the suspected contamination origin.

For hepatitis E virus acquired locally in developed countries, it is generally very difficult to definitely identify the source of infection. Due to the long incubation period of up to 60 days, potentially implicated foods or environmental samples for analyses often will not be available for analysis. HEV can remain infectious at temperatures used in some cooking regimes, although inactivation by heating at 71 degrees Celsius for 20 min has been demonstrated. HEV infectivity can also be reduced using chlorine (hypochlorite) as a disinfectant. Cell culture propagation of HEV has been difficult. Different cell types and culture methods have been used for the development of an efficient cell culture system 
which is needed to better assess HEV stability and inactivation and to elucidate the HEV transmission routes in susceptible populations.

\subsection{Epidemiology of the Disease and Pathogen(s)}

\subsection{Global Burden of Disease}

Hepatitis E virus is a main cause of epidemic hepatitis in developing countries and single cases of hepatitis in higher income countries. According to WHO reports there are 20 million hepatitis E infections, over three million acute cases of hepatitis E, and 57,000 hepatitis E-related deaths every year globally.

\subsubsection{Global distribution}

The different HEV genotypes show a distinct geographical distribution (Lu et al., 2006). Hepatitis E virus strains of genotype 1 are predominantly isolated from hepatitis E patients in Asian and African countries, both from sporadic cases and from outbreak-cases. Genotype 2 HEV-strains have been observed during outbreaks in Mexico, Nigeria and Chad. Genotype $3 \mathrm{HEV}$-strains are commonly associated with locally acquired hepatitis E cases in North-America, Europe, Africa, Japan and China. Genotype 4 strains of HEV are observed mostly in sporadic cases of hepatitis $E$ in developed countries in Asia, such as Japan and Taiwan, but also in developing countries such as Indonesia, China and Vietnam.

\subsubsection{Symptomology (morbidity and mortality ratios)}

Hepatitis E virus infections in humans cannot be distinguished from other forms of hepatitis based on clinical symptoms solely. Serologic or molecular evidence is required for confirmation of a HEV infection. The general symptoms of hepatitis are anorexia, jaundice and liver enlargement (Panda et al., 2007). Furthermore, about half the patients with hepatitis E display abdominal pain and tenderness, nausea and fever. Hepatitis E is mostly selflimiting and in general does not progress to chronicity (Jameel, 1999), although several chronic cases have been reported recently (Gerolami et al., 2008; Kamar et al., 2008). Mortality rates among patients are generally < $0.5 \%$, but may reach up to $25 \%$ in pregnant women for at least genotype 1 (Kumar et al., 2004). The reasons for this high mortality rate in pregnant women are unknown. This feature has not been reported for other genotype cases.

\subsection{Taxonomic Classification of the Agent(s)}

The family Hepeviridae currently is divided into the genera Piscihepevirus (cutthroat trout virus) and Orthohepevirus (all mammalian and avian hepatitis E virus isolates). Species within the genus Orthohepevirus are designated Orthohepevirus A (isolates from human, pig, wild boar, deer, mongoose and camel), Orthohepevirus B (isolates from chicken) Orthohepevirus C (isolates from rat, greater bandicoot, Asian musk shrew, ferret and mink) and
Orthohepevirus D (isolates from bats) (Smith et al., 2013).

HEV variants most closely related to those infecting humans can be divided into at least four genotypes (Panda et al., 2007). Genotypes 1 and 2 only seem to affect humans. Genotype 1 viruses are predominantly isolated from outbreaks and sporadic cases in Asia and Africa, whereas genotype 2 strains mainly have been observed in outbreaks in Mexico and Africa. Genotypes 3 and 4 are zoonotic and are observed in different animal species and sporadic human cases, worldwide for HEV genotype 3 and mainly in Asia for HEV genotype 4.

\subsubsection{Physical description of the agent}

Hepatitis E virus (HEV) consists of a small nonenveloped icosahedral capsid and a single-strand positivesense RNA. The genome of approximately $7.2 \mathrm{~Kb}$ (Tam et al. 1991) is capped at the $5^{\prime}$ end and polyadenylated at the 3 ' end. It contains short stretches of untranslated regions (UTR) at both ends. The HEV genome has three open reading frames (ORFs). ORF1 encodes the non-structural polyprotein (nsp) that contains various functional units: methyltransferase (MeT), papain-like cysteine protease (PCP), RNA helicase (Hel) and RNA dependent RNA polymerase (RdRp) (Chandra et al. 2008). ORF2 encodes the viral capsid protein, the N-terminal signal sequence and glycosylation loci. ORF3 encodes a small regulatory phosphoprotein.

\subsubsection{New variants}

More and more subgenomic sequences of variants isolated from a lot of different, mainly mammalian species become available, but phylogenetic analyses are complicated because reported sequences often overlap over only relatively short regions. Based on analyses of subgenomic regions some of these sequences appear to be more distinct and could represent an additional species. However, it is recommended that assignments of newly detected strains to particular hepevirus species should not be made until comparisons based upon complete genome sequences are available.

The nomenclature of hepatitis E virus (HEV) subtypes in the literature is inconsistent and makes comparison of different studies problematic. Recently a group of researchers have compiled a table of complete genome reference sequences for each subtype to facilitate communication between researchers and help clarify the epidemiology of genotype 1 to 4 Orthohepeviruses. This subtyping procedure might be adopted for other Orthohepevirus taxa (Smith et al., 2016).

\subsection{Transmission}

Faecal-oral and food-borne transmissions, as well as transfusion of infected blood products and vertical (maternal-foetal) transmission are the main routes of $\mathrm{HEV}$ transmission. An example of Materno-fetal transmission of HEV infection has been reported by Aggarwal et al. (2009). HEV-RNA or immunoglobulin (Ig) M anti-HEV antibodies 
have been detected in seven of eight babies born to mothers with acute hepatitis $\mathrm{E}$ in the third trimester of pregnancy (Khuroo et al., 1995)

Blood transfusion HEV infection has been described by Krüttgen et al. (2011). The study reported the youngest ever case: of a five-month-old Caucasian girl presenting with diarrhoea, emesis, and elevated ALT. Surprisingly, acute infection with Hepatitis E virus (HEV) genotype 3 was laboratory-confirmed by reverse transcriptase polymerase chain reaction (RT-PCR) and sequencing (Krüttgen et al., 2011). In HEV endemic as well as non endemic areas, the presence of HEV viremia among healthy blood donors and transmission of this infection to transfusion recipients has been documented (Thapa et al., 2009).

Faecal-oral transmission of HEV occurs primarily through contaminated water in endemic-regions where it is responsible for both sporadic and epidemic outbreaks (Balayan et al., 1983).

\subsubsection{Routes of transmission}

Based on studies on HEV epidemiology in endemic regions there is no doubt that within the human reservoir genotype 1 and 2 viruses are predominantly transmitted via the faecal-oral route, usually through contamination of drinking water (Khuroo, 2010). Regarding HEV human-tohuman transmission there is an increasing number of reports of infection following blood transfusion, the use of blood products or solid organ transplantations (Kamar et al., 2012). All four major genotypes have been detected but genotypes 3 and 4 seem to be involved more frequently. This is likely to be due to the fact that most of these reports are from higher income countries where HEV genotypes 1 and 2 are not endemic. Interfamilial spread of HEVs is not common but multiple cases in one family have been reported (Khuroo 1980; Wong et al., 1980; Arankalle et al., 1995; Wong, et al., 2004; Khuroo 2010). It is suggested that this is due to shared contaminated water rather than person-to-person transmission as the time interval between cases was too short.

Within the swine reservoir faecal-oral transmission has been demonstrated repeatedly (Halbur et al., 2001; Kasorndorkbua et al., 2003, 2004) and it is assumed that this is the major mode of transmission within this species. Since high concentrations of HEV genotype 3 RNA were detected in swine urine also (Bouwknegt et al., 2009; Kasorndorkbua et al., 2004), it is likely that HEVs in swine are transmitted via urine also. Solid data of HEV transmission routes within wildlife reservoirs are not available. An estimation of the likelihood of an HEV specific transmission route has only been made for the faecal-oral route in swine for HEV genotype 3 virus (Bouwknegt et al., 2011). The conclusion of that work was that the faecal oral route is likely to be a main route of transmission but may not be the only route of transmission of HEV genotype 3 virus in swine.

In Europe, HEV, in particular genotype 3 is implicated in transfusion-transmitted HEV infections. In a number of countries in Europe a high prevalence of HEV RNA and specific IgG antibodies has been observed indicating that viral circulation is important. This observation implies a risk for recipients of blood product (Hewitt et al., 2014). Especially in solid organ transplant patients this is a serious risk. Due to immunosuppressive therapy infection individuals may be unable to clear the virus. A chronic HEV infection may be established and supportive therapy with antiviral therapeutics will be needed and may be life-saving (Haagsma et al., 2008).

\subsubsection{Reservoirs}

During interepidemic periods in HEV endemic areas the genotype 1 and genotype 2 viruses may persist in the form of serial transmission among susceptible individuals who have sporadic or subclinical hepatitis E. Hepatitis E viruses are identified in an increasing number of animal species. First detections in animals were reported in swine, chicken and deer in 1997, 2001, and 2003 respectively (Meng et al., 1997; Haqshenas et al., 2001; Tei et al., 2003). More recently HEV sequences have also been detected in rats, wild boar, monkeys, mongoose, rabbits, ferrets, cutthroat trout and bats (Batts et al., 2011; Drexler et al., 2012; Johne et al., 2010; Kaci et al., 2008; Liu et al., 2013; Nidaira et al., 2012; Raj et al., 2012; Zhao et al., 2009). All of these animal species potentially are natural hosts of HEV but just a few of these species have been identified as true reservoirs of HEVs. Defining a true reservoir as a population in which the pathogen can be permanently maintained and from which it is shed to a defined target population (Haydon et al., 2002), presumably this far only domestic swine, wild boar and deer should be regarded as true reservoirs of zoonotic HEVs. Only for domestic swine it has been proven in an experimental setting that HEV can persistently circulate within a closed animal population (Bouwknegt et al., 2008b). HEV does not seem to cause clinical disease in animals other than primates but subclinical infection and mild hepatitis due to $\mathrm{HEV}$ genotype 3 and 4 have been reported in swine (Halbur et al., 2001; Hakze et al., 2011). Since HEV prevalences in pig production regions as well as within herds of domestic swine often are very high (>60\%), domestic swine are almost certainly the main source of direct zoonotic transmission. HEV genotype 3 viruses are detected in domestic swine in about all developed countries where this has been looked for, and in a number of studies it has been shown that contact exposure to swine is a main risk factor for HEV infection. Seroprevalences in swine farmers, slaughterhouse workers and swine veterinarians are significantly higher compared to the general population (Bouwknegt et al., 2008a; Krumbholz et al., 2012).

\subsubsection{Incubation period}

The hepatitis E incubation period is 4-5 weeks based on an oral infection study in human volunteers (Balayan et al., 1983; Chauhan et al., 1993). Viral excretion in faeces begins approximately 1 week prior to the onset of illness and persist for 2-4 weeks, in some cases RT-PCR has yielded positive results until 52 days after onset (Arora et al., 1996). The viremia can be detected in the first 2 weeks after the onset of illness (Chauhan et al., 1993; Clayson et 
al., 1995; Nanda et al., 1995). Viral excretion and viremia has been detected by RT-PCR also prior to liver abnormalities, which normally appear with an increment of aminotransferase, and reaches a peak by the end of the first week. Simultaneously the humoral immune responses appear. Anti-HEV IgM or IgG levels are detected by enzyme immunoassay (Jameel et al., 1999; Aggarwal et al., 2000b). Anti-HEV IgM appears during clinical illness and then gradually disappears over a few months (4-5 months). Some days later than IgM, anti-HEV IgG appears and persists for few years (Dawson et al., 1992; Favorov et al., 1992). The exact persistence of anti-HEV in the sera is still unclear. One study observed that 14 years after acute HEV infection anti-HEV were still circulating in $47 \%$ of patients (Khuroo et al., 1993). To diagnose acute HEV infection antiHEV IgM is a useful tool, whereas IgG anti-HEV does not necessarily indicate recent HEV infection (Aggarwal et al., 2000a).

\subsubsection{Period of communicability}

\subsubsection{Shedding levels}

In HEV infected individuals the virus can be shed enterically at high concentrations. Before the onset of disease symptoms up to $1 \times 10^{5} \mathrm{HEV}$ genome copies per gram faeces can be excreted for several days ( $\mathrm{Li}$ et al., 2006). The concentration of viable virus in an environmental or food matter inoculum may be an important factor in the outcome of clinical hepatitis $\mathrm{E}$ infection (Teo et al., 2010).

It has been estimated that the infectivity titre of HEV for macaques is 10,000-fold higher when inoculated intravenously compared with when it is ingested (Meng, 2003). Clinical signs of hepatitis E are dose-dependent in these animal models and production of disease may require challenge doses 1,000 times or more greater than that required for infection (Emerson and Purcell, 2003). It has been postulated that blood borne HEVs may be more infectious than faecally excreted viruses because ORF3 proteins and cellular membranes are dissociated from the virion after shedding into the bile duct (Okamoto, 2011, 2013).

\subsubsection{Distributions}

In a hepatocarcinoma cell line (PLC/PRF/5) using a faecal suspension with high load of Hepatitis E virus (HEV) $\left(2.0 \times 10^{7}\right.$ copies $/ \mathrm{ml}$, genotype 3$)$, a highest titre of $8.6 \times 10^{7}$ copies $/ \mathrm{ml}$ on day 60 after inoculation could be reached (Okamoto 2011). In swine, HEV RNA has also been detected in urine and it has been suggested that this may play a role in HEV transmission within this animal reservoir (Bouwknegt et al., 2009; Kasorndorkbua et al., 2004). Aerosol transmission of hepatitis $E$ virus has not been reported. However, if infectious HEV is excreted via urine, this route of transmission might be possible too.

\subsubsection{Population susceptibility}

IgG anti-HEV seroprevalences are age dependent and differences between geograpghical region are reported repeatedly (Takeda et al., 2010). Often relatively higher IgG anti-HEV prevalences are found in men.

\subsection{Population and Individual Control Measures}

\subsubsection{Vaccines}

Full-length or truncated forms of the ORF2 protein expressed in bacterial, insect, yeast, animal and plant cells have emerged as potential HEV vaccine candidates.

\subsubsection{Types of vaccines}

Two ORF2 protein expression products been shown to be efficacious in phase II/III clinical trials (Shrestha et al., 2007; Zhu et al., 2010). An alternative approach is a DNA vaccine administered either alone or with the addition of protein to augment the immune response. The advantage of DNA vaccination is its stability and ease of preparation (Thomas et al., 2011) (Haffar et al., 2015).

\subsubsection{Vaccine candidates}

First, a $56 \mathrm{kDa}$ truncated HEV ORF2 protein has been produced from a recombinant baculovirus that forms viruslike particles. This vaccine has undergone safety and efficacy studies in humans. In a randomized, double-blind, placebo controlled, phase II trial in Nepal sponsored by SmithKline Beecham Biologicals (now GlaxoSmithKline: GSK, Brentford, UK), anti-HEV negative healthy adults from the Nepalese Army were randomized to receive either three doses of $20 \mu \mathrm{g}$ of $56 \mathrm{kDa}$ vaccine or placebo at 0,1 , and 6 months, and were followed for an average of 804 days. The vaccine was well-tolerated and highly immunogenic, with $95.5 \%$ of the study subjects acquiring significant antibody titre (95\% CI: 85.6-98.6) (Shrestha et al., 2007).

This study had several limitations. First, virtually all the study subjects were young men (mean age 25 years). Second, this study focused on clinical disease rates and did not look at the HEV infection rate. Third, anti-HEV antibodies titre had declined significantly by the end of the study, so that nearly $44 \%$ of subjects had antibody titres below what is considered protective (Thomas et al., 2011).

Nonetheless, the publication of this first successful clinical trial of an efficacious HEV vaccine generated enthusiasm and optimism. However, this vaccine has not reached the market because of concerns regarding its ability to generate sufficient revenue.

Second, a Chinese company (Xiamen Innovax Biotech, Xiamen, China) has developed another hepatitis $\mathrm{E}$ vaccine and, dubbed the HEV 239 vaccine. HEV 239 is a $26 \mathrm{kDa}$ protein encoded by ORF2 of HEV1, expressed in Escherichia coli, and presents as virus-like particles of 23 $\mathrm{nm}$ in diameter.

In a large scale, randomized, double-blind, placebo controlled, phase III trial in 11 townships in eastern China, 112,604 healthy men and women, aged 16-65 years, were 
randomized to receive either three intramuscular injections of $30 \mu \mathrm{g}$ of HEV 239 at 0,1 , and 6 months or hepatitis B vaccine as a placebo, and were followed for 13-months after the third dose (Zhu et al., 2010). The vaccine was welltolerated and protected against $\mathrm{HEV}$, with an efficacy of 100\% after the second and third dose (95\% CI: 72.1-100.0). No vaccine-related adverse events were documented. The predominance of HEV genotype 4 in this region demonstrated the cross-protective efficacy of the HEV 239 vaccine, which is based on genotype 1 . However, the efficacy of this vaccine against genotype 3 is yet unknown (Riveiro-Barciela et al., 2013). The study endpoint was clinical disease rate rather than $\mathrm{HEV}$ infection rate. Moreover, the persistence of the protection conferred by the vaccine was not studied. This study did not assess the safety of the vaccine in pregnant women, people younger than 15 years or older than 65 years, or in chronic liver disease patients.

In a more recent study, Zhang et al. (2013) showed that, although naturally occurring immunity against HEV lowered the subsequent infection risk significantly (to $0.52 \%$ ), the administration of Hecolin ${ }^{\circledR}$ provided greater protection with an ensuing HEV infection risk of $0.3 \%$ (Zhang et al., 2013). In December 2011, the China Food \& Drug Administration approved the HEV vaccine Hecolin ${ }^{\circledR}$ for use in subjects older than 16 years (Wu et al., 2012). This was the first commercially available hepatitis E vaccine, at that time sold in China at a cost of 110 Renminbi ( $\sim 17.6$ US dollars) per dose (Riedmann et al., 2012). It is unclear whether this vaccine will be developed in other countries.

\subsubsection{Target populations}

Hepatitis E virus vaccination would be most used in developing countries where the virus is endemic, especially in high-risk groups such as pregnant women in the second and third trimesters, the elderly and children less than 2 years of age. The vaccine may also have a role in HEV outbreaks. Since vaccine efficacy after two doses is nearly $100 \%$, protection occurs quickly and can be obtained by two doses given within 1 month (Thomas et al., 2011).

In developed countries, vaccination may also be useful in high-risk groups such as blood recipients, food industry workers, immunosuppressed patients and those with chronic liver disease, as well as travellers to endemic areas. In some studies, HEV infection may portend deleterious consequences for patients with chronic liver disease, and mortality in this subpopulation may be as high as $75 \%$ Ramachandran et al., 2004; Kumar et al., 2004). Although HEV genotype 1 comprises the majority of these infections, genotype 3 in developed countries has been shown to cause hepatic decompensation portending a worse prognosis.

Immunosuppressed patients are also potential candidates (e.g. chemotherapy patients, transplant recipients, HIV infected individuals) because HEV infection in these patients could lead to chronic liver damage (Dalton et al., 2007).
Backer et al. (2012) studied the transmission dynamics of Hepatitis E virus in domecstic pigs. Two transmission models were compared, assuming that animals are infected either locally by their group mates or globally by any infectious animal regardless of its group. Local median transmission rates, that is the number of new infections over the total exposed, ranged from 0.3 to 0.5 per day. Global transmission ranged from 0.2 to 0.91 per day. The mean infectious periods were 24 (18-33) days and 27 (20-39) days and the reproduction numbers were 2.7 (2.2-3.6) and 4.3 (2.8-6.9). Based on these results, global transmission is considered to be the more conservative model. Taking into account the assessed transmission rates in swine it is indicated to look into options for intervention through vaccination in swine populations.

\subsubsection{Worldwide coverage rates}

A vaccine to prevent hepatitis $E$ virus infection has been developed and is licensed in China, but is not yet available elsewhere. The licensed vaccine was tested in a field trial in China. More than 56,000 randomly assigned healthy adults, aged 16 to 65 , got three shots of the hepatitis E vaccine. At the same time, a similar number of adults were injected with the hepatitis B vaccine (the "control" group). During the 4.5 years of follow-up, 60 people developed hepatitis E. Seven were among those who received the hepatitis $\mathrm{E}$ vaccine, and 53 cases developed in those given the hepatitis B vaccine. In a Phase III trial involving 97,356 healthy participants aged 16 to 65 years in China's Jiangsu province, half of the participants were given the vaccine, while the other half received a placebo. In the year following the administration of the third dose, 15 participants in the placebo group developed hepatitis $\mathrm{E}$ compared with none in the vaccine group, with vaccine efficacy after three doses reported as 100 percent (Zhu et al., 2010). Use of this vaccine outside China has not been recommended yet but could be considered during major outbreaks.

\subsubsection{Vaccination strategies}

Das et al. (2001) constructed a Markov model using decision analysis techniques to evaluate three different strategies regarding the early form of $\mathrm{HEV}$ vaccination in a Monte Carlo simulation cohort of 10,000 healthy young individuals living in endemic areas: A- Universal vaccination, B- Screening and vaccination, and C- No vaccination. The cost of illness consisted of the direct cost of treatment, as well as the indirect cost of lost workdays. Vaccine-induced immunity was presumed to last at least eight years. Outcome parameters consisted of the incremental cost-effectiveness ratio, as well as the discounted cost per patient and quality adjusted life years (QALY) gained in each strategy. The cost-effectiveness $(\mathrm{C} / \mathrm{E})$ ratio for plans $\mathrm{A}, \mathrm{B}$, and $\mathrm{C}$ was $\$ 0.33, \$ 0.50$, and $\$ 0.53$ respectively. The authors estimated the cost of vaccine to be $\$ 9.86$ which is almost half of the anticipated price of Hecolin ${ }^{\circledR}$ (Riedmann et al., 2012). Based on the previous data, it seems that universal vaccination against HEV could be highly cost-effective with a marginal cost- 
effectiveness ratio below the currently available viral hepatitis vaccines. However, a Markov model analysis based on Hecolin ${ }^{\circledR}$ is needed, when additional data become available (Wierzba et al., 2012).

Backer et al. (2012), modelled HEV vaccination in swine production. Three effects of vaccination were explored separately. When vaccination is not sufficient to eliminate the virus, a shorter mean infectious period decreases the fraction of infectious animals at slaughter age, whereas a reduced transmission rate parameter adversely increases it. With a reduced susceptibility, vaccination of animals at a later age can be a better strategy than early vaccination. These effects should be taken into account in vaccine development and vaccination strategies.

\subsubsection{Hygiene measures}

Preventing hepatitis $\mathrm{E}$ in endemic areas depends primarily on providing clean drinking water and proper sanitation. Boiling water before consumption appears to reduce the risk of acute hepatitis $E$. Chlorine has an effect on HEV infectivity, but the conditions for chlorine treatment need to be studied further to elucidate its feasibility in practice. More research is required in the area of HEV inactivation to improve our understanding of the transmission routes of HEV and also to develop control strategies for HEV contamination and infection (Cook and Van der Poel, 2015) . Isolation of affected persons is not indicated as person-to-person transmission is uncommon. (Aggarwal et al., 1994) The protective role of anti-HEV antibodies in humans requires further study. No reduction in disease rates could be shown in pre or postexposure prophylaxis studies among recipients of immunoglobulin preparations manufactured in hepatitis E-endemic areas. (Khuroo et al., 1992; Joshi et al., 1985). In a recent study, administration of immune serum globulin to pregnant women during an outbreak has been shown to reduce the total number of de novo HEV infections, although the number of clinical cases has remained unchanged (Arankalle et al., 1998) Thus, further research is required to elucidate the role of immune serum globulin in HEV prevention. There have been ongoing experiments in HEV vaccine development using recombinant protein and complementary DNA corresponding to HEV capsid protein which demonstrated that the vaccines can induce the development of anti-HEV (He et al., 1997; Purdy et al., 1993).

Accumulating data indicate that sporadic HEV infections are mediated by the consumption of uncooked or undercooked animal meat or foods made with pig organs such as liver. In Japan, considerable cases of fulminant hepatitis $E$ have been reported after consumption of meats and entrails of pigs, wild boars, and deer (Masuda et al., 2005; Miyashita et al., 2012; Tei et al., 2003). Consumption of raw seafood, pork liver sausage, and exposure to wild boars are proposed as major risk factors associated with HEV infection in Italy (La Rosa et al., 2011). One of the risk factors for HEV infection in France is the ingestion of raw pork liver sausage, which has been reported to contain infectious HEV particles (Bouwknegt et al., 2007; Colson et al., 2010; Berto et al., 2013a). In addition, HEV was detected in muscle samples in experimentally infected pigs (Bouwknegt et al., 2009). In Korea, there has been a single instance of fulminant $\mathrm{HEV}$ infection in a patient who consumed raw bile juice from wild boar (Kim et al., 2011). The genetic sequence of HEV isolated from the patient matched genotype 4 swine HEV. These data clearly suggest swine HEV is mainly transmitted to humans through the consumption of under-cooked or raw pork meat and liver products.

Eating raw shellfish is another risk factor for human HEV infections. About $9 \%$ of oysters collected from the coastal regions of Korea harboured HEV whose sequence matched genotype 3 swine HEV (Song et al., 2010). These and other data indicate that raw shellfish cultivated in sewage-contaminated waters may be a significant source of HEV infection in humans (Balayan et al., 1993).

To prevent sporadic HEV infection of food borne origin people should be advised to thoroughly cook potentially HEV contaminated foods and in particular pork products before consumption. However, this will interfere with certain eating habits especially in the case of shellfish.

\subsection{Environmental Occurrence, Persistence, and Survival}

\subsection{Detection methods}

Enzyme-linked immunosorbent assays (ELISA), conventional reverse transcriptase PCR (RT-PCR) and real time RT-PCR, cell culture, confocal microscopy and electron microscopy have been used for detection or confirmation of HEV infection. These methods differ significantly in their sensitivity and specificity. The commonly used methods for HEV detection are described below in more detail.

HEV recombinant proteins and synthetic peptides, corresponding to immunodominant epitopes of the ORF2 and ORF3 structural proteins of the virus, have been sourced as the capturing antigen (Emerson and Purcell, 2003) in Immunoassays. Commercially available ELISAs have improved in recent years, but it is suspected that some of the earlier prevalence data reflected subclinical infections and serological cross-reactivity that may have contributed to a high seroprevalence in the non-endemic areas (Krawczynski and Aggarwal et al., 2000; Emerson and Purcell, 2003).

Conventional RT-PCR assays are currently utilized in direct diagnosis of HEV. The samples collected may be faeces, serum (from animal or human), cultures of infected cells or post mortem tissue highly positive as bile and liver (Panda and Thakral, 2007; Varma et al., 2011). Real-time PCR (RT-PCR) is becoming the most popular method for direct detection of HEV in clinical samples. The technique enables both detection and confirmation of specificity genotyping. In addition, RT-PCR is a sensitive tool in epidemiological investigations since that this technique is fast and reliable. The full viral genome of HEV was cloned in 1991 (Tam and Smith et al. 1991). Since then several 
pairs of primers have been designed to amplify various segments of the genome. The primers are mainly designed to the conserved regions (helicase, polymerase and the terminal fragment of ORF2) of the HEV genome (Panda and Thakral, 2007). The development of RT-PCR, whereby the accumulation of the PCR amplicon can be detected in realtime, has allowed for the quantification of HEV.

The lack of an efficient and reliable cell culture system and a practical animal model for HEV have hindered studies on mechanisms of HEV replication, transmission, pathogenesis and environmental survival.

Okamoto in 2011 described for the first time, a cell culture system capable of secreting infectious HEV in high titres into culture media (Okamoto, 2011). The success with the original JE03-1760F virus strain has been extended to other strains that can support the replication of HEV with an even higher efficiency, and can be passaged through many generations (Okamoto, 2011). Okamoto was able to infect PLC/PRF/5 cells with both sera and faeces of patients and observe high HEV titre in the cell culture system (Okamoto, 2011).

There are several reports in the literature demonstrating the potential of a new 3D culture system Rotating Wall Vessel (RWV) (Nickerson and Goodwin et al. 2001), for the growth of fastidious viruses. This 3D culture system has been used to grow fastidious Norovirus from faecal materials (Kageyama and Kojima, 2003), and recently it was demonstrated that the system can also be used for in vitro cultivation of HEV (Berto et al., 2013b).

\subsection{Data on occurrence}

\subsubsection{Excreta in environment}

Up to $10^{5} \mathrm{HEV}$ genome copies per gram faeces can be excreted for several days. Hepatitis E virus is also found in high concentrations (HEV sequences can be detected by reverse transcription polymerase chain reaction (RT-nested PCR)) in pig manure. As pig manure is used for composting, HEV sequences will be detected at the start of this process. However in the final products (compost) samples from compost plants, destined to be commercialized as a soil fertilizer, HEV sequences are not detected, suggesting that composting is a suitable method to eliminate HEV and thus, to reduce the transmission of HEV from pigs to humans (Garcia et al., 2014).

\subsubsection{Sewage}

In a lot of different studies and different regions the occurrence of hepatitis $E$ virus in sewage has been assessed through testing and monitoring of urban sewage (Table 1). In many of these studies HEV was detected and often the concerning hepatitis $E$ virus strains were characterized using molecular methods. Identified genotypes depend on the region under survey and multiple genotypes may be involved. In Europe genotype 3 viruses are often identified in sewage but genotype 1 viruses are reported also (Clemente-Casares et al., 2009). The latter is assumed to be due to travel related infections. In developing countries in Africa and Asia primarily genotype 1 viruses are identified in sewage (Hazam et al., 2010) but genotype 3 or genotype 4 viruses are also reported to be found in urban sewage.

Table 1. Natural occurrence of HEV in sewage

\begin{tabular}{|c|c|c|c|c|c|c|}
\hline Area & Study Period & Genotypes & Sample Type & $\begin{array}{l}\text { Percent Positive } \\
\text { (\# of Samples) }\end{array}$ & $\begin{array}{c}\text { Concentration } \\
\text { Averages (GC/L) }\end{array}$ & Reference \\
\hline $\begin{array}{l}\text { India } \\
\text { (Gokulpuri) }\end{array}$ & NR & NR & Raw Sewage & $\begin{array}{c}4.3 \% \\
(6 / 141)\end{array}$ & NR & $\begin{array}{c}\text { Hazam et al., } \\
2010\end{array}$ \\
\hline $\begin{array}{l}\text { Israel } \\
\text { ( Haifa, Tel } \\
\text { Aviv, Beer } \\
\text { Sheva) }\end{array}$ & 2013 to 2015 & 3 & Raw Sewage & $\begin{array}{c}8.7 \% \\
(14 / 160)\end{array}$ & NR & $\begin{array}{l}\text { Ramachandran } \\
\text { et al., } 2016\end{array}$ \\
\hline Italy & 2008 to 2009 & 1 and 3 & Raw Sewage & $\begin{array}{c}16.1 \% \\
(19 / 118)\end{array}$ & NR & $\begin{array}{l}\text { La Rosa et al., } \\
2010\end{array}$ \\
\hline Norway & 2008 to 2009 & 1 and 3 & $\begin{array}{l}\text { Raw and } \\
\text { Treated } \\
\text { sewage }\end{array}$ & $\begin{array}{c}7.8 \% \\
(8 / 102)\end{array}$ & $\begin{array}{c}\text { Under } \\
\text { 1.3E+04 (Limit } \\
\text { of quantification) }\end{array}$ & $\begin{array}{l}\text { Myrmel et al., } \\
2015\end{array}$ \\
\hline $\begin{array}{l}\text { Pakistan } \\
\text { (Faisalabad) }\end{array}$ & NR & 1 & Raw Sewage & $\begin{array}{c}15 \% \\
(3 / 20)\end{array}$ & NR & $\begin{array}{l}\text { Ahmad et al., } \\
2015\end{array}$ \\
\hline $\begin{array}{l}\text { Spain } \\
\text { ( Llobregat } \\
\text { river) }\end{array}$ & 2011 to 2012 & NR & Raw sewage & $\begin{array}{c}13.8 \% \\
(27 / 196)\end{array}$ & NR & $\begin{array}{l}\text { Rusinol et al., } \\
2015\end{array}$ \\
\hline Switzerland & 2010 & 1 and 3 & Raw Sewage & $\begin{array}{c}54.8 \% \\
(17 / 31)\end{array}$ & $7.81 \mathrm{E}+04$ & $\begin{array}{l}\text { Masclaux et } \\
\text { al., } 2013\end{array}$ \\
\hline
\end{tabular}




\subsubsection{Surface water}

Several studies have reported the detection of hepatitis E (HEV) virus in surface waters (Table 2). HEVs may occur in water environments when raw sewage is contaminated by infected individuals and the virus follows the route through treated effluent to the surface waters receiving wastewater discharges (Iaconelli et al., 2015).

Table 2. Natural occurrence of HEV in surface waters

\begin{tabular}{|c|c|c|c|c|c|c|}
\hline Area & Study Period & Genotypes & Sample Type & $\begin{array}{l}\text { Percent Positive } \\
\text { (\# of Samples) }\end{array}$ & $\begin{array}{c}\text { Concentration } \\
\text { Range } \\
\text { (GC/L) }\end{array}$ & Reference \\
\hline $\begin{array}{l}\text { Japan } \\
\text { (Hokkaido) }\end{array}$ & 2003 to 2005 & 3 & Sea water & $\begin{array}{c}2.7 \% \\
(1 / 37)\end{array}$ & NR & $\begin{array}{l}\text { Ishida et } \\
\text { al., } 2012\end{array}$ \\
\hline $\begin{array}{l}\text { Netherlands } \\
\text { (Meuse } \\
\text { river) }\end{array}$ & 2004 to 2005 & 3 & $\begin{array}{c}\text { Surface } \\
\text { water (river) }\end{array}$ & (12) & NR & $\begin{array}{l}\text { Rutjes et } \\
\text { al., } 2009\end{array}$ \\
\hline $\begin{array}{l}\text { Philippines } \\
\text { (River in } \\
\text { Manila city) }\end{array}$ & 2012 to 2013 & 3 & $\begin{array}{c}\text { Surface } \\
\text { water (river) }\end{array}$ & $\begin{array}{c}50 \% \\
(6 / 12)\end{array}$ & NR & $\begin{array}{l}\text { Li et al., } \\
2014\end{array}$ \\
\hline $\begin{array}{l}\text { United } \\
\text { States } \\
\text { (Buckeye, }\end{array}$ & 2011 to 2012 & NR & $\begin{array}{c}\text { Surface } \\
\text { water (lake) }\end{array}$ & $\begin{array}{c}45 \% \\
(9 / 20)\end{array}$ & $\begin{array}{c}9.00 \text { to } \\
2.99 \mathrm{E}+02\end{array}$ & $\begin{array}{l}\text { Givens et } \\
\text { al., } 2016\end{array}$ \\
\hline
\end{tabular}

NR: Not Reported

\subsubsection{Ground water}

On farms where HEV RNA is detected in swine feces, it can also be found in stored liquid waste (Kase et al., 2009), and HEVs excreted by human patients may also contaminate water sources. It has been suggested liquid wastes from either human or animal origin may lead to HEV contaminations of ground water but clear detections of HEVs in ground waters used for drinking water or cleaning water are not reported in literature.

\subsubsection{Drinking water}

Fecal contamination of drinking water is the commonest cause of HEV outbreaks in developing countries. In these countries Hepatitis E virus infection major causes of viral hepatitis and has been responsible for waterborne epidemics. The higher risk of public health, it is a major area of concern, particularly in regions that have witnessed episodes of such epidemics from time to time.

\subsubsection{Seawater}

As Hepatitis E virus (HEV) is an enteric pathogen of both humans and animals which is excreted by infected individuals it can be present in wastewaters and coastal waters. However it is not known if such contamination can result in infections through bathing water or may lead to contaminations of tap water.

\subsubsection{Sludge}

The first report that HEV could be detected in sewage was published more than 20 years ago (Jothikumar et al., 1993). Subsequent reports describe the frequent detection of HEV in sewage from France (25\%), Switzerland (32\%), India (56\%), and Spain (32-43\%). Described figures differ per country for various reasons (Clemente-Casares et al., 2003)

\subsubsection{Soil}

A study in Spain investigated the presence of HEV in pig manure composting plants. Samples were taken from the different stages of composting treatment in these plants : slurry reception ponds, anaerobic ponds, aerobic ponds, fermentation zone and composting final products. HEV was detected by reverse transcription polymerase chain reaction (RT-nested PCR) in four ( $80 \%)$ of five plants studied, mainly in the first stages of the process (Garcia et al., 2014).

\subsubsection{Irrigation water and on crops}

Hepatitis E virus genogroup 3 sequences have been detected on irrigated, field-grown strawberries. Irrigation water was suspected as the contamination origin but this was not proven by analyis of the used irrigation water (Brassaard et al., 2012). In another study by Maunula et al. (2013) frozen raspberries were found to be HEVcontaminated $(2.6 \%)$. In this study animal fecal contamination was evidenced by positive pAdV and bPyV 
assay results.

\subsubsection{Fish and shellfish}

Bivalve molluscan shellfish are known to concentrate viral particles during filtration undertaken as part of their feeding process. A large variety of human enteric viruses, includin hepatitis $\mathrm{E}$ virus have been detected in different shellfish species during either environmental studies or outbreak investigations. Few outbreaks have been reported until now (Grodzki et al., 2014).

\subsubsection{Air}

Hepatitis E virus airborne transmission has not been identified as an important transmission route. In air samples from waste water treatment plant, using quantitative polymerase chain reaction (qPCR) detection methods during two different seasons and two consecutive years, HEV was not detected. Since HEV excretion in pig urine has been detected and this could be a transmission route in swine herds. It should therefore not be ignored that HEV might be transmitted via aerosols. However it is unsure if can play a role in human environmental exposure under natural conditions.

\subsection{Persistence}

There are significant gaps in our knowledge regarding the survival of HEV in the environment (including food contact surfaces), and also regarding the effect of elimination procedures used. The lack of a reliable infectivity assay has hampered extensive study. There is very little information available on the survival of hepatitis E virus; it could survive in harsh conditions, although inactivation by heating at $70^{\circ} \mathrm{C}$ for 20 minutes has been demonstrated (Cook and Van der Poel, 2015). Other methods used for HEV inactivation include UV treatment, and chlorine or hypoclorite treatment. Monitoring detectable genome copies by RT-PCR revealed a reduction of genomic copies, indicating an effect of the disinfectant methods, but depending on the concentrations of the disinfectants and in case of UV inactivation was not complete. It can be concluded that chlorine does have an effect on HEV infectivity but the conditions for chlorine treatment need to be studied further to elicidate its feasiblity in practice.

\subsection{Reductions by Sanitation Management}

\subsection{Wastewater Treatment}

Whereas contamination of drinking water has long been identified as the main mode of transmission for $\mathrm{HEV}$ genotype 1 and genotype 2 strains in developing countries, the attributive role of drinking water in the number HEV genotype 3 and genotype 4 infection events is still unknown. However, since HEV genotype 3 and genotype 4 have been detected in surface waters (rivers and lakes) there is increasing attention for HEV removal by sanitation practices in industrialized countries as well an interest on controlling this pathogen as new wastewater treatment is put into place in developing regions of the world.

Guerrero-Latorre et al. (2016) evaluated the ability of UV radiation and flocculation-chlorination sachets to reduce HEV in water matrices. UV irradiation tests using low-pressure radiation showed inactivation kinetics for HEV by $4 \log _{10}$ with a UV fluence of $23 \mathrm{~mJ} / \mathrm{cm}^{2}$. The flocculationchlorination sachet preparations significantly reduced viral concentrations in water matrices, although the inactivation results were under the baseline of reduction $\left(4.5 \log _{10}\right)$ proposed by WHO guidelines.

Verma et al., (2009) tested different domestic water purification units and found that HEV log reduction was often inadequate. Best results were obtained using a hollow fibre membrane unit and a gravity-fed filter unit: $6.53 \log _{10}$ reduction values.

No data are available on observable HEV removals by pit Latrines, vault toilets or dry toilets, septic tanks, wetlands, aerated lagoons. In such situations other RNA viruses that could serve as surrogates for HEV may give an impression of the efficiency of removal.

\subsubsection{Composting of fecal wastes}

Garcia et al. (2014) did not detect HEV in any final product samples from five pig manure composting plants in Spain (using a nested RT-PCR assay) destined to be commercialized as a soil fertilizer. This may suggest that composting is a suitable method to eliminate HEV and thus, to avoid contamination of surface waters and reduce the transmission of HEV from pigs to humans.

\subsubsection{Wastewater treatment facilities}

Hepatitis E virus is frequently detected in waste water treatment plant influent (La Fauci et al., 2010; Myrmel et al., 2015). In treated sewage reported HEV detections vary largely and virus $\log _{10}$ reduction values are often not determined. The performance of membrane bioreactors (MBR) is also studied with regard to HEV and removal by MBR is reported, but it is unclear what virus log reduction levels are reached.

Bearing in mind the numbers of HEV infections in humans which still seem to increase in industrialized countries, it is important to try to prevent transmissions via water even if this seems a lower risk than contaminated food products from swine and human to human infection is seldom reported for HEV genotype 3 and genotype 4 . In this respect it is indicated to better study the efficiency of HEV removal in waste water treatment facilities for all HEV genotypes. 


\section{References}

Aggarwal, R. and Kini, D. (2000). Duration of viraemia and faecal viral excretion in acute hepatitis E. Lancet. 356, pp. 1081-1082.

Aggarwal, R. and Krawczynski, K. (2000). Hepatitis E: an overview and recent advances in clinical and laboratory research. Journal of Gastroenterology and Hepatology. 15, pp. 9-20.

Aggarwal, R. and Naik, S. (2009). Epidemiology of hepatitis E: current status. Journal of Gastroenterology and Hepatology. 24, pp. 1484-1493.

Aggarwal, R. and Naik, S.R. (1994). Hepatitis E: intrafamilial transmission versus waterborne spread. Journal of Hepatology. 21, pp. 718-723.

Ahmad, T., Anjum, S., Zaidi, N.S., Ali, A., Afzal, M.S. and Arshad, N. (2015). Frequency of hepatitis E and Hepatitis A virus in water sample collected from Faisalabad, Pakistan. Annals of Agricultural and Environmental Medicine. 22(4), pp. 661-664.

Albiñana-Gimenez, N., Clemente-Casares, P., Calgua, B., Huguet, J.M., Courtois, S., Girones, R. et al. (2009). Comparison of methods for concentrating human adenoviruses, polyomavirus JC and noroviruses in source waters and drinking water using quantitative PCR. Journal of Virological Methods. 158, Department of Microbiology, Faculty of Biology, University of Barcelona, Barcelona, Spain. pp. 104-9. doi: 10.1016/j.jviromet.2009.02.004.

Arankalle, V.A., Chadha, M.S., Dama, B.M., Tsarev, S.A., Purcell, R.H. and Banerjee, K. (1998). Role of immune serum globulins in pregnant women during an epidemic of hepatitis E. Journal of Viral Hepatitis. 5, pp. 199-204.

Arankalle, V.A. and Tsarev, S.A. (1995). Age-specific prevalence of antibodies to hepatitis A and E viruses in Pune, India, 1982 and 1992. The Journal of Infectious Diseases. 171, pp. 447-450.

Arora, N.K. and Nanda, S.K. (1996). Acute viral hepatitis types E, A, and B singly and in combination in acute liver failure in children in north India. Journal of Medical Virology. 48, pp. 215-221.

Backer, J.A., Berto, A., McCreary, C., Martelli, F. and van der Poel, W.H. (2012). Transmission dynamics of hepatitis E virus in pigs: estimation from field data and effect of vaccination. Epidemics. 4, pp. 86-92.

Balayan, M.S. (1993). Hepatitis E virus infection in Europe: regional situation regarding laboratory diagnosis and epidemiology. Clinical and Diagnostic Virology. 1, pp. 1-9.

Balayan, M.S. and Andjaparidze, A.G. (1983). Evidence for a virus in non-A, non-B hepatitis transmitted via the fecal-oral route. Intervirology. 20, pp. 23-31.

Batts, W., Yun, S., Hedrick, R. and Winton, J. (2011). A novel member of the family Hepeviridae from cutthroat trout (Oncorhynchus clarkii). Virus Research. 158, pp. 116-123. 
Berto, A., Grierson, S., van der Honing, H.R., Martelli, F., Johne, R., Reetz, J. et al. (2013). Hepatitis E virus in pork liver sausage, France. Emerging Infection Diseases. 19, pp. 264-266.

Berto, A., van der Poel, W.H., van der Honing, H.R., Martelli, F., La Ragione, R.M., Inglese, N. et al. (2013). Replication of hepatitis E virus in three-dimensional cell culture. Journal of Virological Methods. 187, pp. 327-332.

Bouwknegt, M., Engel, B., Herremans, M.M., Widdowson, M.A., Worm, H.C., Koopmans, M.P. et al. (2008). Bayesian estimation of hepatitis $\mathrm{E}$ virus seroprevalence for populations with different exposure levels to swine in The Netherlands. Epidemiology and Infection. 136, pp. 567-576.

Bouwknegt, M. and Frankena, K. (2008). Estimation of hepatitis E virus transmission among pigs due to contact-exposure. Veterinary Research. 39, pp. 40.

Bouwknegt, M. and Lodder-Verschoor, F. (2007). Hepatitis E virus RNA in commercial porcine livers in The Netherlands. Journal of Food Protection. 70, pp. 2889-2895.

Bouwknegt, M., Rutjes, S.A., Reusken, C.B., Stockhofe-Zurwieden, N., Frankena, K., De Jong, M.C. et al. (2009). The course of hepatitis E virus infection in pigs after contact-infection and intravenous inoculation. BMC Vetinary Research. 5, pp. 7-19.

Bouwknegt, M., Teunis, P.F., Frankena, K., De Jong, M.C. and De Roda Husman, A.M. (2011). Estimation of the likelihood of fecal-oral HEV transmission among pigs. Risk Analysis: an Official Publication of the Society for Risk Analysis. 31, pp. 940-950.

Boyer, T., Sanyal, A.J., Terrault, N.A. and Lindor, K.D. (2011). Zakim and Boyer's Hepatology: A Textbook of Liver Disease. 6th edition Saunders. Philadelphia, PA.

Brassard, J., Gagné, M.J., Généreux, M. and Côté, C. (2012). Detection of human food-borne and zoonotic viruses on irrigated, field-grown strawberries. Applied and Environmental Microbiology. 78, pp. 3763-3766.

Chandra, V. and Taneja, S. (2008). Molecular biology and pathogenesis of hepatitis E virus. Journal of Biosciences. 33, pp. 451-464.

Chauhan, A. and Jameel, S. (1993). Hepatitis E virus transmission to a volunteer. Lancet. 341, pp. 149-150.

Clayson, E.T. and Innis, B.L. (1995). Detection of hepatitis E virus infections among domestic swine in the Kathmandu Valley of Nepal. The American Journal of Tropical Medicine and Hygiene. 53, pp. 228-232.

Clemente-Casares, P., Pina, S., Buti, M., Jardi, R., Martín, M., Bofill-Mas, S. et al. (2003). Hepatitis E virus epidemiology in industrialized countries. Emerging Infection Diseases. 9, pp. 448-454.

Colson, P. and Borentain, P. (2010). Pig liver sausage as a source of hepatitis E virus transmission to humans. The Journal of Infectious Diseases. 202, pp. 825-834. 
Virology. 7, pp. 189-194.

Dalton, H.R., Hazeldine, S., Banks, M., Ijaz, S. and Bendall, R. (2007). Locally acquired hepatitis E in chronic liver disease. Lancet. 369, pp. 1260.

Dawson, G.J. and Chau, K.H. (1992). Solid-phase enzyme-linked immunosorbent assay for hepatitis E virus IgG and IgM antibodies utilizing recombinant antigens and synthetic peptides. Journal of Virological Methods. 38, pp. 175-186.

Drexler, J.F., Seelen, A., Corman, V.M., Tateno, F.A., Cottontail, V., Zerbinati, M.R. et al. (2012). Bats worldwide carry hepatitis E virus-related viruses that form a putative novel genus within the family Hepeviridae. Journal of Virology. 86, pp. 9134-9147.

Emerson, S.U. and Purcell, R.H. (2003). Hepatitis E virus. Reviews in Medical Virology. 13, pp. 145-154.

Favorov, M.O. and Fields, H.A. (1992). Serologic identification of hepatitis E virus infections in epidemic and endemic settings. Journal of Medical Virology. 36, pp. 246-250.

Wang, H., Yang, C.L., Jiang, H.M., Cai, J.P., Wang, Y.J., Ai, X. et al. (2010). Efficacy and safety of a recombinant hepatitis E vaccine in healthy adults: a large-scale, randomised, double-blind placebo-controlled, phase 3 trial. Lancet. 376, (FC, Z., ed.). pp. 895-902.

Gérolami, R., Moal, V. and Colson, P. (2008). Chronic hepatitis E with cirrhosis in a kidney-transplant recipient. The New England Journal of Medicine. 358, pp. 859-860.

García, M., Fernández-Barredo, S. and Pérez-Gracia, M.T. (2014). Detection of hepatitis E virus (HEV) through the different stages of pig manure composting plants. Microbial biotechnology. 7, pp. 26-31.

Gascon, J., Alvarez, M., Valls, M.E., Bordas, M.J., Jimenez de Anta, T.M. and Corachan, M. (2001). Cyclosporiasis: a clinical and epidemiological study in travellers with imported Cyclospora cayetanensis infection. Medicina Clinica. 116, pp. 451-464.

Givens, C.E., Kolpin, D.W., Borchardt, M.A., Duris, J.W., Moorman, T.B. and Spencer, S.K. (2016). Detection of hepatitis E virus and other livestock-related pathogens in Iowa streams. The Science of the Total Environment. 1(566-567), pp. 1042-51.

Grodzki, M., Schaeffer, J., Piquet, J.C., Le Saux, J.C., Chevé, J., Ollivier, J. et al. (2014). Bioaccumulation efficiency, tissue distribution, and environmental occurrence of hepatitis E virus in bivalve shellfish from France. Applied and Environmental Microbiology. 80, pp. 4269-4276.

Guerrero-Latorre, L., Gonzales-Gustavson, E., Hundesa, A., Sommer, R. and Rosina, G. (2016). UV disinfection and flocculation-chlorination sachets to reduce hepatitis E virus in drinking water. International Journal of Hygiene and Environmental Health. 219(4-5), pp. 405-11. 
Haagsma, E.B. and van den Berg, A.P. (2008). Chronic hepatitis E virus infection in liver transplant recipients. Liver Transplantation. 14, pp. 547-553.

Haffar, S., Bazerbachi, F. and Lake, J.R. (2015). Making the case for the development of a vaccination against hepatitis E virus. Liver International. 35, pp. 311-316.

Halbur, P.G. and Kasorndorkbua, C. (2001). Comparative pathogenesis of infection of pigs with hepatitis E viruses recovered from a pig and a human. Journal of Clinical Microbiology. 39, pp. 918-923.

Haqshenas, G. and Shivaprasad, H.L. (2001). Genetic identification and characterization of a novel virus related to human hepatitis E virus from chickens with hepatitis-splenomegaly syndrome in the United States. The Journal of General Virology. 82, pp. 2449-2462.

Haydon, D.T., Cleaveland, S., Taylor, L.H. and Laurenson, M.K. (2002). Identifying reservoirs of infection: a conceptual and practical challenge. Emerging Infection Diseases. 8, pp. 1468-1473.

Hazam, R.K., Singla, R., Kishore, J., Singh, S., Gupta, R.K. and Kar, P. (2010). Surveillance of hepatitis E virus in sewage and drinking water in a resettlement colony of Delhi: what has been the experience?. Archives of Virology. 155, pp. 1227-1233.

He, J., Hoffman, S.L. and Hayes, C.G. (1997). DNA inoculation with a plasmid vector carrying the hepatitis E virus structural protein gene induces immune response in mice. Vaccine. 15, pp. 357-362.

Hewitt, P.E., Ijaz, S., Brailsford, S.R., Brett, R., Dicks, S., Haywood, B. et al. (2014). Hepatitis E virus in blood components: a prevalence and transmission study in southeast England. Lancet. 384, pp. 1766-1773.

Iaconelli, M., Purpari, G., Libera, S.D., Petricca, S., Guercio, A., Ciccaglione, A.R. et al. (2015). Hepatitis A and E Viruses in Wastewaters, in River Waters, and in Bivalve Molluscs in Italy. Food and Environmental Virology. 7, pp. 316-324.

Ishida, S., Yoshizumi, S., Ikeda, T., Miyoshi, M., Goto, A., Matsubayashi, K. et al. (2012). Detection and molecular characterization of hepatitis E virus in clinical, environmental and putative animal sources. Archives of Virology. 157(12), pp. 2363-8.

Jameel, S. (1999). Molecular biology and pathogenesis of hepatitis E virus. Expert Reviews In Molecular Medicine. pp. $1-16$.

Johne, R. and Plenge-Bonig, A. (2010). Detection of a novel hepatitis E-like virus in faeces of wild rats using a nested broadspectrum RT-PCR. The Journal of General Virology. 91, pp. 750-758.

Joshi, Y.K., Babu, S., Sarin, S., Tandon, B.N., Gandhi, B.M. and Chaturvedi, V.C. (1985). Immunoprophylaxis of epidemic non-A non-B hepatitis. The Indian Journal of Medical Research. 81, pp. 18-19.

Jothikumar, N., Aparna, K., Kamatchiammal, S., Paulmurugan, R., Saravanadevi, S. and Khanna, P. (1993). Detection of hepatitis $\mathrm{E}$ virus in raw and treated wastewater with the polymerase chain reaction. Applied and Environmental Microbiology. 59, pp. 2558-2562. 
Kaci, S., Nöckler, K. and Johne, R. (2008). Detection of hepatitis E virus in archived German wild boar serum samples. Veterinary Microbiology. 128, pp. 380-385.

Kageyama, T. and Kojima, S. (2003). Broadly reactive and highly sensitive assay for Norwalk-like viruses based on realtime quantitative reverse transcription-PCR. Journal of Clinical Microbiology. 41, pp. 1548-1557.

Kamar, N., Legrand-Abravanel, F., Izopet, J. and Rostaing, L. (2012). Hepatitis E virus: what transplant physicians should know. American Journal of Transplantation. 9, pp. 2281-2287.

Kamar, N. and Selves, J. (2008). Hepatitis E virus and chronic hepatitis in organ-transplant recipients. The New England Journal of Medicine. 358, pp. 811-817.

Kase, J.A., Correa, M.T. and Sobsey, M.D. (2009). Detection and molecular characterization of swine hepatitis E virus in North Carolina swine herds and their faecal wastes. Journal of Water and Health. 7, pp. 344-357.

Kasorndorkbua, C., Guenette, D.K., Huang, F.F., Thomas, P.J., Meng, X.J. and Halbur, P.G. (2004). Routes of transmission of swine hepatitis E virus in pigs. Journal of Clinical Microbiology. 42, pp. 5047-5052.

Kasorndorkbua, C., Thacker, B.J., Halbur, P.G., Guenette, D.K., Buitenwerf, R.M., Royer, R.L. et al. (2003). Experimental infection of pregnant gilts with swine hepatitis E virus. Canadian Journal of Veterinary Research. 67, pp. 303-306.

Khuroo, M.S. (2010). Seroepidemiology of a second epidemic of hepatitis $\mathrm{E}$ in a population that had recorded first epidemic 30 years before and has been under surveillance since then. Hepatology International. 4, pp. 494-499.

Khuroo, M.S. (1980). Chronic liver disease after non-A, non-B hepatitis. Lancet. 2, pp. 860-861.

Khuroo, M.S. and Dar, M.Y. (1992). Hepatitis E: evidence for person-to-person transmission and inability of low dose immune serum globulin from an Indian source to prevent it. Indian Journal of Gastroenterology. 11, pp. 113-116.

Khuroo, M.S. and Kamili, S. (1995). Vertical transmission of hepatitis E virus. Lancet. 345, pp. 1025-1026.

Khuroo, M.S. and Kamili, S. (1993). Hepatitis E and long-term antibody status. Lancet. 341, pp. 1355.

Kim, Y.M. and Jeong, S.H. (2011). The first case of genotype 4 hepatitis E related to wild boar in South Korea. Journal of Clinical Virology. 50, pp. 253-256.

Krüttgen, A., Scheithauer, S., Häusler, M. and Kleines, M. (2011). First report of an autochthonous hepatitis E virus genotype 3 infection in a 5 month old female child in Germany. Journal of Clinical Virology. 50, pp. 175-176.

Krawczynski, K. and Aggarwal, R. (2000). Hepatitis E. Infectious Disease Clinics of North America. 14, pp. 669-687.

Krumbholz, A., Mohn, U., Lange, J., Motz, M., Wenzel, J.J., Jilg, W. et al. (2012). Prevalence of hepatitis E virus-specific antibodies in humans with occupational exposure to pigs. Medical Microbiology and Immunology. 201, pp. 239-244. 
Kumar, A., Beniwal, M., Kar, P., Sharma, J.B. and Murthy, N.S. (2004). Hepatitis E in pregnancy. International Journal of Gynaecology and Obstetrics. 85, pp. 240-244.

La Fauci, V., Sindoni, D., Grillo, O.C., Calimeri, S., D Giudice, L. and Squeri, R. (2010). Hepatitis E virus (HEV) in sewage from treatment plants of Messina University Hospital and of Messina City Council. Journal of Preventive Medicine and Hygiene. 51(1), pp. 28-30.

La Rosa, G., Muscillo, M., Vennarucci, V.S., Garbuglia, A.R., La Scala, P. and Capobianchi, M.R. (2011). Hepatitis E virus in Italy: molecular analysis of travel-related and autochthonous cases. The Journal of General Virology. 92, pp. 1617-1626.

Li, T.C., Yang, T., Shiota, T., Yoshizaki, S., Yoshida, H., Saito, M. et al. (2014). Molecular detection of hepatitis E virus in rivers in the Philippines. The American Journal of Tropical Medicine and Hygiene. 90(4), pp. 764-6.

Liu, P., Bu, Q.N., Wang, L., Han, J., Du, R.J., Lei, Y.X. et al. (2013). Transmission of hepatitis E virus from rabbits to cynomolgus macaques. Emerging Infection Diseases. 19, pp. 559-565.

Li, X., Kamili, S. and Krawczynski, K. (2006). Quantitative detection of hepatitis E virus RNA and dynamics of viral replication in experimental infection. Journal of Viral Hepatitis. 13, pp. 835-839.

Lu, L. and Li, C. (2006). Phylogenetic analysis of global hepatitis E virus sequences: genetic diversity, subtypes and zoonosis. Reviews in Medical Virology. 16, pp. 5-36.

Masclaux, F.G., Hotz, P., Friedli, D., Savova-Bianchi, D. and Oppliger, A. (2013). High occurrence of hepatitis E virus in samples from wastewater treatment plants in Switzerland and comparison with other enteric viruses. Water Research. 47, pp. 5101-5109. doi: 10.1016/j.watres.2013.05.050.

Masuda, J., Yano, K., Tamada, Y., Takii, Y., Ito, M., Omagari, K. et al. (2005). Acute hepatitis E of a man who consumed wild boar meat prior to the onset of illness in Nagasaki, Japan. Hepatology Research. 31, pp. 178-183.

Maunula, L., Kaupke, A., Vasickova, P., Söderberg, K., Kozyra, I., Lazic, S. et al. (2013). Tracing enteric viruses in the European berry fruit supply chain. International Journal of Food Microbiology. 167, pp. 177-185.

Meng, X.J. (2003). Swine hepatitis E virus: cross-species infection and risk in xenotransplantation. Current Topics in Microbiology and Immunology. 278, pp. 185-216.

Meng, X.J., Purcell, R.H., Halbur, P.G., Lehman,J.R., Webb, D.M., Tsareva, T.S. et al. (1997). A novel virus in swine is closely related to the human hepatitis. Proceedings of the National Academy of Sciences of the United States of America. 94, pp. 9860-9865.

Miyashita, K., Kang, J.H., Saga, A., Takahashi, K., Shimamura, T., Yasumoto, A. et al. (2012). Three cases of acute or fulminant hepatitis $\mathrm{E}$ caused by ingestion of pork meat and entrails in Hokkaido, Japan: Zoonotic food-borne transmission of hepatitis E virus and public health concerns. Hepatology Research. 42, pp. 870-878.

Myrmel, M., Lange, H. and Rimstad, E. (2015). A 1-Year Quantitative Survey of Noro-, Adeno-, Human Boca-, and Hepatitis E Viruses in Raw and Secondarily Treated Sewage from Two Plants in Norway. Food and Environmental Virology. 7(3), pp. 213-23. 
Nanda, S.K. and Ansari, I.H. (1995). Protracted viremia during acute sporadic hepatitis E virus infection. Gastroenterology. 108, pp. 225-230.

Nickerson, C.A. and Goodwin, T.J. (2001). Three-dimensional tissue assemblies: novel models for the study of Salmonella enterica serovar Typhimurium pathogenesis. Infection and Immunity. 69, pp. 7106-7120.

Nidaira, M., Takahashi, K., Ogura, G., Taira, K., Okano, S., Kudaka, J. et al. (2012). Detection and phylogenetic analysis of hepatitis E viruses from mongooses in Okinawa, Japan. The Journal of Veterinary Medical Science. 74, pp. 1665-1668.

Okamoto, H. (2013). Culture systems for hepatitis E virus. Journal of Gastroenterology. 48, pp. 147-158.

Okamoto, H. (2011). Efficient cell culture systems for hepatitis E virus strains in feces and circulating blood. Reviews in Medical Virology. 21, pp. 18-31.

Panda, S.K. and Thakral, D. (2007). Hepatitis E virus. Reviews in Medical Virology. 17, pp. 151-180.

Purdy, M.A., McCaustland, K.A., Krawczynski, K., Spelbring, J., Reyes, G.R. and Bradley, D.W. (1993). Preliminary evidence that a trpE-HEV fusion protein protects cynomolgus macaques against challenge with wild-type hepatitis E virus (HEV). Journal of Medical Virology. 41, pp. 90-94.

Raj, V.S., Smits, S.L., Pas, S.D., Provacia, L.B., Moorman-Roest, H., Osterhaus, A.D. et al. (2008). Novel hepatitis E virus in ferrets, the Netherlands. Emerging Infection Diseases. 18, pp. 1369-1370.

Ramachandran, J.1., Eapen, C.E., Kang, G., Abraham, P., Hubert, D.D., Kurian, G. et al. (2004). Hepatitis E superinfection produces severe decompensation in patients with chronic liver disease. Journal of Gastroenterology and Hepatology. 19, pp. 134-138.

Riedmann, E.M. (2012). Chinese biotech partnership brings first hepatitis E vaccine to the market. Human Vaccines and Immunotherapeutics. 8, pp. 1743-1744.

Riveiro-Barciela, M., Rodríguez-Frías, F. and Buti, M. (2013). Hepatitis E virus: new faces of an old infection. Annals of Hepatology. 12, pp. 861-870.

Rusinol, M., Fernandez-Cassi, X., Timoneda, N., Carratalà, A., Abril, J.F., Silvera, C. et al. (2015). Evidence of viral dissemination and seasonality in a Mediterranean river catchment: Implications for water pollution management. Journal of Environmental Management. 159, pp. 58-67.

Rutjes, S.A., Lodder, W.J., Lodder-Verschoor, F., van den Berg, H.H., Vennema, H., Duizer, E. et al. (2009). Sources of hepatitis E virus genotype 3 in The Netherlands. Emerging Infection Diseases. 15(3), pp. 381-7.

Shrestha, M.P. and Scott, R.M. (2007). Safety and efficacy of a recombinant hepatitis E vaccine. The New England Journal of Medicine. 356, pp. 895-903.

Smith, D.B., Purdy, M.A. and Simmonds, P. (2013). Genetic variability and the classification of hepatitis E virus. Journal of Virology. 87, pp. 4161-4169. 
Smith, D.B., Simmonds, P., Izopet, J., Oliveira-Filho, E.F., Ulrich, R.G., Johne, R. et al. (2016). Proposed reference sequences for hepatitis E virus subtypes. The Journal of General Virology. 97(3), pp. 537-42.

Song, Y.J., Jeong, H.J., Kim, Y.J., Lee, S.W., Lee, J.B., Park, S.Y. et al. (2010). Analysis of complete genome sequences of swine hepatitis E virus and possible risk factors for transmission of HEV to humans in Korea. Journal of Medical Virology. 82, pp. 583-591.

Takeda, H., Matsubayashi, K., Sakata, H., Sato, S., Kato, T., Hino, S. et al. (2010). A nationwide survey for prevalence of hepatitis E virus antibody in qualified blood donors in Japan. Vox Sanguinis. 99, pp. 307-313.

Tam, A.W. and Smith, M.M. (1991). Hepatitis E virus (HEV): molecular cloning and sequencing of the full-length viral genome. Virology. 185, pp. 120-131.

Tei, S. and Kitajima, N. (2003). Zoonotic transmission of hepatitis E virus from deer to human beings. Lancet. 362, pp. 371-373.

Teo, C.G. (2010). Much meat, much malady: changing perceptions of the epidemiology of hepatitis E. Clinical Microbiology and Infection. 16, pp. 24-32.

Thapa, R.1., Biswas, B., Mallick, D. and Ghosh, A. (2009). Acute pancreatitis-complicating hepatitis E virus infection in a 7year-old boy with glucose 6 phosphate dehydrogenase deficiency. Clinical Pediatrics. 48, pp. 199-201.

van der Honing, H.R. and van Coillie, E. (2011). First isolation of hepatitis E virus genotype 4 in Europe through swine surveillance in the Netherlands and Belgium. PLoS One. 6, pp. e22673.

Varma, S.P., Kumar, A., Kapur, N., Durgapal, H., Acharya, S.K. and Panda, S.K. (2011). Hepatitis E virus replication involves alternating negative- and positive-sense RNA synthesis. The Journal of General Virology. 92(Pt 3), pp. 572-81.

Verma, V. and Arankalle, V.A. (2009). Virological evaluation of domestic water purification devices commonly used in India emphasizes inadequate quality and need for virological standards. Tropical Medicice and International Health. 14(8), pp. 885-9.

Wierzba, T.F. and Panzner, U. (2012). Report on the International Symposium on Hepatitis E, Seoul, South Korea, 2010. Emerging Infectious Diseases. 18, pp. e1.

Wong, D.C., Purcell, R.H., Sreenivasan, M.A.,,. and Pavri, K.M. (1980). Epidemic and endemic hepatitis in India: evidence for a non-A, non-B hepatitis virus aetiology. Lancet. 2, pp. 876-879.

Wong, K.H. and Liu, Y.M. (2004). Epidemiology of hepatitis A and hepatitis E infection and their determinants in adult Chinese community in Hong Kong. Journal of Medical Virology. 72, pp. 538-544.

Wu, T., Li, S.W., Zhang, J., Ng, M.H., Xia, N.S. and Zhao, Q. (2012). Hepatitis E vaccine development: a 14 year odyssey. Human Vaccines and Immunotherapeutics. 8, pp. 823-827. 
Zhang, J., Zhang, X.F., Zhou, C., Wang, Z.Z., Huang, S.J., Yao, X. et al. (2013). Protection against hepatitis E virus infection by naturally acquired and vaccine-induced immunity. Clinical Microbiology Infectious Diseases. 20, pp. 397-405.

Zhao, K. and Liu, Q. (2009). Screening of specific diagnostic peptides of swine hepatitis E virus. Virology Journal. 6, pp. 186. 